\title{
What makes a competent psychologist?
}

Citation for published version (APA):

Roe, R. A. (2002). What makes a competent psychologist? European Psychologist, 7(3), 192-203. https://doi.org/10.1027//1016-9040.7.3.192

Document status and date:

Published: 01/01/2002

DOI:

10.1027//1016-9040.7.3.192

Document Version:

Publisher's PDF, also known as Version of record

\section{Please check the document version of this publication:}

- A submitted manuscript is the version of the article upon submission and before peer-review. There can be important differences between the submitted version and the official published version of record.

People interested in the research are advised to contact the author for the final version of the publication, or visit the DOI to the publisher's website.

- The final author version and the galley proof are versions of the publication after peer review.

- The final published version features the final layout of the paper including the volume, issue and page numbers.

Link to publication

\footnotetext{
General rights rights.

- You may freely distribute the URL identifying the publication in the public portal. please follow below link for the End User Agreement:

www.umlib.nl/taverne-license

Take down policy

If you believe that this document breaches copyright please contact us at:

repository@maastrichtuniversity.nl

providing details and we will investigate your claim.
}

Copyright and moral rights for the publications made accessible in the public portal are retained by the authors and/or other copyright owners and it is a condition of accessing publications that users recognise and abide by the legal requirements associated with these

- Users may download and print one copy of any publication from the public portal for the purpose of private study or research.

- You may not further distribute the material or use it for any profit-making activity or commercial gain

If the publication is distributed under the terms of Article $25 \mathrm{fa}$ of the Dutch Copyright Act, indicated by the "Taverne" license above, 


\title{
What Makes a Competent Psychologist?
}

\author{
Robert A. Roe \\ University of Nijmegen, The Netherlands
}

\begin{abstract}
In developing European standards for the psychological profession, two main approaches to the definition of professional competence have been proposed. One focuses on the roles and functions psychologists should be able to perform (output model), the other on the educational curricula that should be followed in order to become a psychologist (input model). This article starts with a discussion of both approaches, which leads to the conclusion that neither of them offers a sufficient base for setting adequate professional standards. Next a comprehensive model of occupa-
\end{abstract}

tional competence is presented which comprises both input and output factors. It is indicated how this model can be utilized in defining competence profiles for the psychological specialties, as well as in developing and maintaining competence. Issues covered include: student selection, academic curriculum design, initial professional training, continued professional training, institutional and individual accreditation, and quality assurance.

\section{Introduction}

Over the years interest has grown in the qualities psychologists must have in order to successfully exercise their profession, and in the way to achieve these qualities. It has increasingly become recognized that an agreed-upon definition of these qualities is essential in order to evaluate and improve existing training programs, and to develop a shared system of quality assurance for the psychologist's professional practice. This is particularly relevant in a politically and economically unifying Europe where educational and employment mobility is an important policy aim. As with other professions the European Commission has supported efforts toward greater harmonization of psychology curricula at European universities and the development of common professional standards for European psychology. As early as 1989 the European Network of Organizational and Work Psychologists was given a grant to carry out a survey and to develop a curriculum framework in work and organizational psychology (Roe et al., 1994; ENOP, 1998). A working group of European psychologists, performing similar activities for the education of psychologists in general, has recently published a report titled "EuroPsyT, A Framework for Education and Training for Psychologists in Europe" (Lunt, 2000; Lunt et al., 2001a). A second working group has begun to develop a system of accreditation that will include a European diploma in psychology.

One of the questions that arises from the attempt to define the qualities of psychologists is whether to concentrate on what must be taught to students in order for them to become competent psychologists, or on the competences trained psychologists should demonstrate in order to qualify for independent practice. In order words, should one focus on the "input" or on the "output" of the system by which psychologists are prepared for practice? A related question is how to define and measure the various qualities to be attained. In this article I discuss briefly the advantages and limitations of input

Robert A. Roe graduated from the University of Amsterdam, The Netherlands, and has been Professor of Work and Organizational Psychology at Delft University of Technology and Tilburg University. $\mathrm{He}$ is currently part-time Professor of Organizational Psychology at the University of Nijmegen and an organizational consultant. He was the Founding President of the European Association of Work and Organizational Psychology and Director of the Work \& Organization Research Center in Tilburg. He is involved in the preparation of a European Diploma for Psychology as member of the EuroPsyT project team.

Correspondence concerning this article should be addressed to Prof Dr. R. A. Roe, University of Nijmegen, Department of Work \& Organizational Psychology, P. O. Box 9104, NL-6500 HE Nijmegen, The Netherlands (tel. +31 24 361-2639, fax +31 24 361-5937, e-mail R.Roe@psych.kun.nl). 
and output models and describe the differences between these types of models in terms of competences. I then introduce a comprehensive model of competence developed earlier (Roe, 1999b; Roe, 2001, 2002) and demonstrate that it can help to successfully link input and output models. Subsequently, I discuss the steps needed to build a comprehensive competence profile for the psychological profession and briefly review our current knowledge about the competences required. Finally, I mention some potential applications of the competence model in building up a system for developing and maintaining the psychological profession.

\section{The Psychologist at Work}

While psychologists have extensively studied other people's work, they have given limited attention to their own work. Relatively few publications have addressed the content of the psychological profession. See for some reference texts Peterson et al. (1992), BPS (1995), Pryzwansky and Wendt (1999), and Hartley and Branthwaite (2000). Although there are a number of possible definitions, I choose to define a psychologist as "an academically educated professional who helps clients to understand and solve problems by applying the theories and methods of psychology." Thus, the route to the profession, i. e., the academic education, is a key element in the definition of the psychologist. As with other professions there are many specialties within the psychological profession. Thus, it is customary to differentiate between clinical psychologists, work and organizational psychologists, educational psychologists, and child psychologists. But there are also references to the health psychologist, traffic psychologist, sport psychologist, forensic psychologist, and economic psychologist (e. g., Anastasi, 1979; Roe, 1984). Two important observations should be made: First, there is no single systematic basis for differentiating between the specialties. The major areas of specialization differ with respect to the role of the clients or subjects, the institutional setting in which they are placed, the type of problems addressed, client behavior being identified as normal or abnormal, etc. Second, there is no such thing as a "general practitioner" in psychology: All professional psychologists somehow practice as a specialist. In this respect psychology resembles the engineering profession and differs from the medical profession.

Both points are of relevance when it comes to defining the qualifications of the professional psychologist.
Because there is no clear systematic basis for differentiating between the specialties, it is difficult to identify common and unique qualifications of all psychologists. And since there is no overlap between the specialties in the form of a "general psychologist," one can only infer common elements from a comparison between them. Thus, the commonalities between the child psychologist and the work and organizational psychologist have to be found by abstracting from the actual work situation, the work object, and the activities of the respective psychologists. This means that one is forced to use generic terms such as "diagnosing," "assessing," or "developing an intervention plan," which apply to almost any professional situation-and to ignore the fact that, say, the analysis of the family situation of a child and the analysis of a worker's job call for very different activities and techniques.

Another way to cope with the situation is to look for common elements in the educational curricula that lead to the qualification of psychologist in the respective fields. In this case one has to rely on terms that describe educational content or methods, such as "course in social psychology" or "practicum in multivariate statistics." In view of the fact that curricula are often differentiated according to specialty, the curricular commonalities are also to be found at a somewhat abstract level- e.g., "data collection" or "paper writing."

The need for abstraction in defining the profession is amplified when considering psychologists who are educated and employed in different countries. Despite a growing convergence during the last two decades, one can still observe significant differences among the European countries (as well as with countries in other parts of the world). Differences exist, for example, in the duration of total curriculum, nonpsychological content, the degree of specialization, the treatment of theory and practice, etc. (e.g., Newstead \& Makkinen, 1997; Green, Wolf \& Leney, 1999). Likewise, there are substantial differences in the occupational settings in which psychologists operate. The settings may be characterized by such aspects as the prevalence of employment over independent practice, the influence of government on practice, the scope of legal and other regulations, the protection of the title of psychologist, the relative position in competition with other professions (e. g., the medical profession), the power of professional bodies and trade unions, etc. (see, e.g., Pulverich, 1997; Lunt et al., 2001b). Such differences may mean that clinical psychologists in Norway, Belgium, and Greece perform very different work activities, despite 
the fact that they all draw from the same knowledge base. It should be noted that some psychological specialties, such as community psychologist, occupational psychologist, and engineering psychologist, may be known in a particular country or region only and not in all European countries.

Thus, it appears that defining the qualifications of the psychologist is by no means a simple affair. Our brief discussion brings us to the heart of the problem of how to capture the distinctive features of the profession, i. e., by a so-called input model or an output model.

\section{Input and Output Models}

If it is our aim describe and standardize the qualifications of psychologists in Europe, we may pursue two main avenues: We can either concentrate on the educational route that provides the legal right to call oneself a psychologist or provides qualifications for independent practice; or we can look at the competences that psychologists must have in order to perform their role properly. The first approach has been adopted by the ENOP working group that developed standards for European work and organizational psychology (Roe et al., 1994; ENOP, 1998) as well as by the EuroPsyT team, which formulated standards for psychology as a whole (Lunt et al., 2001a). The second approach has been followed by Bartram (1996, 2000a, 2000b) and others (BPS, 2001; Consultative Working Group, 1998; NCVQ, 1991, 1995) in the UK.

At first sight, the input model has an obvious practical advantage. Since an academic education is seen as a prerequisite for becoming a psychologist in all European countries, and since curricular content is typically codified and readily available, this is by far the easiest and fastest route to achieve some degree of standardization. Although this route is not without effort or difficulty, it is at least feasible. Since one can largely rely on available information and on university-based control systems, the costs of applying an input system are limited. A second advantage is one that touches upon a fundamental issue, i. e., the essential autonomy inherent in all learned professions-psychology included-which implies that the way in which professionals operate in delineating the problem of the client and in applying the knowledge of their discipline should be left to their discretion. Any way of standardizing the output would undermine the intellectual autonomy of the professional and frustrate the need for ongoing in- novation. However, here are also drawbacks to the input approach. First, it only grasps the conditions for attaining a basic level of professional competence and leaves the development of higher levels of competence untouched. Second, it is limited in its effect, since the completion of an academic study in psychology does not guarantee the ability to act successfully as a professional. Even though the occupational setting within each country provides some connection between input and output, there is no guarantee that the output will always meet the standards. Third, comparing educational systems between countries is a demanding task, complicated by cultural and language differences that are not always easy to accommodate.

The primary advantage of an output model, on the other hand, lies in its focus on the competences as demanded by practice. Thus, with proper assessment, it would enable one to ascertain in a direct way whether an individual psychologist does or does not possess a sufficient level of expertise. This makes it easier to guarantee a certain level of qualification to the public and provides indications concerning competence deficits and required improvements in practice. An obvious disadvantage of output models is that the assessment of individual competences is cumbersome, and therefore time consuming and costly. This is particularly true because of the need for cross-cultural assessment. The differences between occupational settings and job content across countries mentioned above makes a system yielding equivalent assessments very difficult to achieve. In addition, there is the difficulty of defining competences in a way that applies to all specialties. Choosing a higher level of abstraction seems to offer a way out, but at the same time reduces much of the operational precision that makes output models more attractive. However, abstraction is not without risk. As I discuss below, it may threaten the very logic of competence assessment. The main drawback follows from the point made earlier, i. e., that fixing outputs may create a conflict with the autonomy that is a defining characteristic of a professional. Delineating and describing competences related to the psychologist's job performance may result in lists of demands that are more easily met by people in related nonacademic professions that lack the feature of professional autonomy than by psychologists themselves. Such a paradoxical outcome would clearly not be to the benefit of the psychological profession or the client. A final limitation of the output model is that it provides little or no information on the educational route to basic professional competence. 


\section{Toward a Comprehensive Model of Competence}

Although different meanings have been assigned to the notion of competence (e.g., Spencer \& Spencer, 1993; Mansfeld, 1996; Fletcher, 1997), there is a growing consensus in the literature that competence should be defined as "a learned ability to adequately perform a task, duty or role" (Roe, 2002). There are two distinguishing features in the notion of competence, i. e., that it relates to a specific type of work to be performed in a particular work setting, and that it integrates several types of knowledge, skill, and attitudes. Examples of competences are making a budget plan (accountant), drafting a contract (lawyer), carrying out a tooth extraction (dentist), providing behavior therapy (clinical psychologist), developing and applying a personnel selection procedure (work and organizational psychologist). Competences are typically acquired in a process of learning-bydoing in the actual work situation, during an internship or in a simulation-based learning situation. It is important to note the differences between competences, on the one hand, and knowledge, skills, and attitudes, on the other hand. The latter differ from competences in that they are more elementary, i. e., they can be developed in isolation, be assessed separately, and applied in multiple competences. Thus, the knowledge of language and mathematics, the skills of speech and writing, and the attitudes of carefulness and service orientation can each be called upon in a variety of work settings and be integrated into multiple competences. Knowledge, skills, and attitudes are typically acquired during one's educational career, in successive scholastic learning situations.

The fact that competences are specific to a particular type of work does not mean that they can always be sharply delineated. The reason is that the boundaries between tasks, duties, and roles are not always clear. For example, tasks may be defined more broadly or more narrowly, depending on the organizational context. In work psychology (e.g., Hacker, 1998) tasks are seen as organized in hierarchies, the higher levels of which-duties and roles-are more specific and the lower levels of which consist of more generic parts. Competences corresponding to lower-level tasks-also called subtasks — can be designated as "generic competences" or "subcompetences." I prefer to use the latter term, in order to indicate that these lower-level competences are normally not sufficient for the performance of any job in organizations, but are called upon in combination with other qualities. Examples of subcompe- tences are competence in using word-processing software, competence in interviewing, and basic leadership competence. They are often learned in scholastic situations as well, but they require practice-oriented techniques such as exercises, assignments, and internships.

Competences should be also be distinguished from abilities, personality traits, and other more stable characteristics of the individual. Such dispositions can be seen as the basis for what the individual learns, that is knowledge, skills, and attitudes, as well as subcompetences and competences. But since the learning process also depends on situational factors and on time, dispositions should not be equated with these learned qualities. The main relationships between all eight concepts are easily communicated by the image of a Greek temple shown in Figure 1.

An important question is how competences relate to performance. While the presence of a high level of competence is a prerequisite for good performance, it does not guarantee adequate performance. It is clear from the extensive literature on performance (e.g., Roe, 1999a; Matthews et al., 2000) that there are many personal and situational factors that have an influence on the way in which individuals perform. Personal factors include motivation, energetic state, and level of vitality. Situational factors comprise technical conditions such as the availability of tools, information and supplies, and social conditions such as social support, leadership, and management. In practical terms, a person who is competent to execute a certain duty may not always perform well, because of lack of motivation, fatigue, illness, or because of lack of proper equipment, absence of relevant

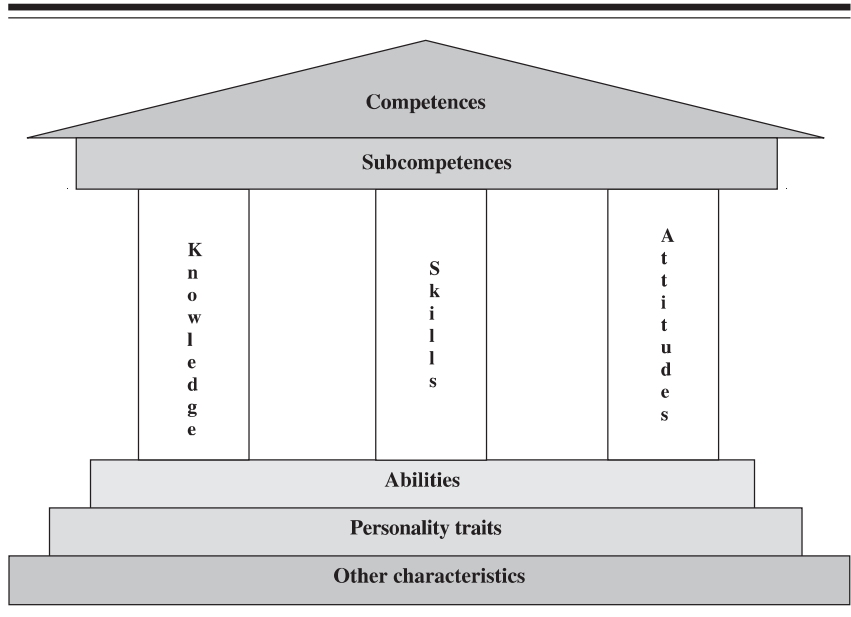

Figure 1

Competence architecture model (Roe, 2002). 
data, deficient leadership, etc. In other words, competence is a necessary, but not a sufficient, condition for performance.

The architectural model of competences presented here, designed to apply to any occupation, may help to answer the question how to delineate the qualifications psychologists should have. One option is to focus on the ingredients from which competences are built, that is, knowledge, skills, and attitudes, as well as subcompetences. These qualities are obtained in the course of the education of the psychology student. The knowledge pertains to the various theories and empirical data produced within the different fields of psychology. The skills apply to oral and written communication, observing and listening, problem analysis, applying statistical methods, using computer software, etc. The attitudes relate to accuracy, integrity, self-criticism, commitment, responsibility, respect and tolerance for others, ethical awareness, service orientation, etc. Subcompetences are broader-in the sense that they overarch and integrate knowledge, skills, and attitudes-but they are also more specific. They relate to the fulfilment of such basic occupational functions as administering tests, conducting interviews, applying group techniques, and searching for literature. Another option is to consider the competences needed to fulfill the professional roles of the psychologist, either at the point of entry into the occupation or at some later stage. Because competences are specific, it is necessary to differentiate between the specialties and take into account the occupational setting (school system, management consulting, public health care), the type of client (child, student, spouse, manager), the sort of problem (individual development, prevention of illness, conflict resolution), etc. This means that every specialty must be described in its own right. Wherever specialties have elements in common, this should show up when following this procedure.

If we look back at the issue of input versus output models, four observations can be made. First, output models address the level of competences and/or subcompetences. In a system such as the National Occupational Standards (NOS) for Applied Psychology (BPS, 2001), which probably represents the most pertinent example of output models, the emphasis appears not to be on the competences, but rather on the subcompetences needed. The NOS specify a range of generic job functions psychologists should be able to fulfill, including: “Establish contact with clients," "provide psychological advice to aid problem solving and decision making," "prepare psychological evidence and produce reports," and "assess the outcomes of the evaluation." The system de- scribes competences in a manner that generalizes across work settings and leaves out the demands of the particular situation. Second, input models appear to focus mainly on knowledge and skills that specify what psychologists should know and be able to do in terms of the educational curriculum to which they must have been exposed, with respect to the time spent on study. However, the ENOP reference model and the EuroPsyT model make an indirect reference to subcompetences, by requiring a research project and practical work in an internship. Third, the relationships between the two types of models follow from the linkages between knowledge and skills, on the one hand, and the subcompetences and competences, on the other hand. The involvement in supervised work during the initial stage of employment as a professional, required by the input model, accounts for the forging of knowledge and skill elements into subcompetences and the development of actual competences as addressed in the output model.

It was already noted that both models have certain limitations in terms of the efforts involved in their construction and application. We can now add that neither model fully grasps the qualities needed for the development and maintenance of professional competence in psychology. This is at least true for the input and output models proposed thus far. Both models neglect the abilities, personality traits, and other characteristics (such as styles, values, interests, physical traits, and biographical characteristics) required for successful completion of the academic and professional learning processes through which one becomes a psychologist. Also, both pay little attention to attitudes. Although one might argue that attitudes are generally underrated in educational systems, and that attitudes are somehow addressed by ethical codes, it is remarkable since attitudes vis-à-vis the client and the profession are perhaps the most outstanding feature differentiating psychologists from other professionals.

I would like to end this section by pointing out a potential risk in the use of output models which may limit their applicability and usefulness. The risk is that instead of describing competences as required in each psychological specialty, one introduces "generalized" descriptions of competence based on what different specialties seem to have in common. Although it may be attractive to use generalized competence statements-and this has become common practice in many modern HRM systems-the effect may be counterproductive and even harmful. The underlying problem may be illustrated by an example from another occupational domain, i. e., aviation. If an output model were to be

European Psychologist, Vol. 7, No. 3, September 2002, pp. 192-202 (C) 2002 Hogrefe \& Huber Publishers 
used for assessing a pilot's ability to fly a Boeing 737, one would consider subcompetences such as reading maps, reading dials, and operating controls, and evaluate competence in flight preparation and flight execution, either during an actual flight in this aircraft or in a simulator. To assess the ability to fly a McDonald Douglas MD-11, one would do the assessment in that particular aircraft or a simulator thereof. Observing either the B-737 pilot or the MD-11 pilot and evaluating their flight competences "in general" or "for any type of aircraft" would produce invalid competence assessments that would be dangerous to rely on. In the case of psychology it would be equally wrong to declare a psychologist competent "in general" or "for any specialty." A psychologist may be fully competent in clinical psychology and be highly incompetent in work and organizational psychology or vice versa. Assessments of generalized competences would hide the differences between specialties and merely produce false and illusory statements about a psychologist's actual qualifications. (Of course, one can give competence assessments a common structure by using generalized statements, provided that each of these is interpreted with reference to a specific work domain and that equivalence is somehow demonstrated.)

\section{Toward a Competence Profile of the Psychologist}

The competence architecture model presented above may serve as a tool to build up a comprehensive "competence profile" of the psychologist. A competence profile is defined as "a list of competences, subcompetences, knowledge, skills, attitudes, abilities, personality traits and other characteristics that are essential for carrying out a job or an occupation." Each of these elements are to be described in terms of content and of level. According to the Integrative Profiling System (Roe, 2001), the following steps should be undertaken to draw-up a competence profile for any occupation:

1. Occupational or job analysis: collecting information on the roles, duties, and tasks to be performed in a particular occupation or job;

2. Competence analysis: establishing the competences required, along with the associated forms of knowledge, skills, and attitudes, as well as the underlying dispositions, i.e., abilities, personality traits, and other characteristics;
3. Competence modeling: drawing-up a model showing the relationships between particular competences, and relevant knowledge, skills, and attitudes, as well as dispositions (e. g., in a statistical form such as the regression model);

4. Testing the competence model: assessing the validity of the model and establishing the parameters of the variables contributing to or predicting competences.

The first two steps can be carried out by conventional methods for job and task analysis (e. g., Gael, 1988; Shepard, 2001). In practice, the judgment of subject matter experts (SME's) and behavior experts is often accepted as a sufficient basis for arriving at the competence profile. The latter two steps can be seen as a refinement and empirical underpinning of the competence profile.

Since psychology is a profession that only exists in specialized forms, a hierarchical approach to competence profiling is imperative. This means that the specialties are to be examined separately, and that competence analysis should be performed for each of them. Considering the diversity in educational arrangements and employment settings in Europe mentioned earlier-and the lack of empirical knowledge about the content of the specialties-there is an urgent need for research into this issue. One can only proceed to competence analysis once the specialties are clearly defined. The analysis can be carried out with respect to different moments in the psychologist's career. I propose to make a distinction between three such career moments, i. e.:

1. The transition point from university to supervised practice, usually after 5 or more years of academic study; the competences present at this moment may be referred to as "basic competences";

2. The transition point from supervised to independent practice, usually after 1 year of supervised work; the competences present at this moment may be referred to as "initial competences";

3. The transition point from junior to senior psychologist, usually after 4 to 5 years of independent practice; the competences present at this moment may be referred to as "advanced competences."

While there are some published studies about the dispositions psychologists should posses and the knowledge and skills they should have (e.g., Francis \& Cameron, 1991; Peterson et al., 1992; Hesketh, 2000), the available evidence is far from sufficient to draw up complete competence profiles of the psychological profession. Figure 2 illustrates what a competence profile would look like 
in the case of a work and organizational psychologist at the point of entry into independent practice. An adequate picture of the competences required by this and other specialties at the three transition points can only be achieved on the basis of sufficient empirical research.

\section{Applications of the Competence Architecture Model}

There are a number of possible uses for the competence model presented above for developing and maintaining professional qualifications of psychologists. These applications include student selection, academic curriculum design, basic professional training, continued professional training, accreditation, and quality assurance in psychological services. Each of these applications can be seen as part of the overall system by which psychologists are educated and developed, and by which the potential of psychology is put at the disposal of people in society. In the following section I discuss how the information to be laid down in the competence profiles of the psychologist help to shape the various components of such a system. This makes clear which data are needed to build up these applications, and it underlines the importance of putting such a competence profile together.

\section{Student Selection}

At the basis of the system of developing psychologists is the selection of students. Whether selection is achieved by an institutional mechanism for the admission of students to university or by self-selection, it is useful to know which qualities candidates need to possess in order to have a sufficient probability of success in education and in the profession itself. To identify the necessary qualities, one would have to look at the lower part of the competence profile, which describes the dispositions as well as the types of knowledge, skills and attitudes which were acquired in earlier life (cf. Figure 2). Thus the lower segment of the profile supplies us with predictor variables that serve to predict characteristics at the higher part of the profile, i. e., types of knowledge, skills, and attitudes to be acquired during the study of psychology, as well the subcompetences and basic competences needed at the point of graduation. The learning achievements with respect to these characteristics can be seen as the criteria in the selection system. From a systems point of view, selection bridges the gap between the qualities of the student at the point of entering the university and the learning demands put on the student during university education. The criteria for success in education and practice may diverge, thus creating the risk that someone who is able to complete the academic curriculum appears to be unsuited for dealing with clients at a later stage. However, in view of the range of areas in which a student can specialize, there is room for a rather broad range of dispositions. As for the nature of the dispositions, it is important to realize that the required dispositions are not limited to abilities but also include personality traits and other characteristics, such as values and interests.

\section{Academic Curriculum Design}

In designing a new curriculum for the study of psychology, or in redesigning an existing curriculum, one has to rely on a different part of the competence profile. The curriculum has to encompass everything the student has to learn in order to successfully enter the field as a beginning psychologist. This includes knowledge, skills, and attitudes-beyond those present at the point of admission to the university-subcompetences common to the main specialties, and perhaps common competences needed to perform during supervised work in any area. The curriculum should be designed in such a way that the gap between the demands at the beginning and the end of the studies are adequately covered. This means that all subject domains should be addressed, and that the educational methods employed provide the necessary opportunities for learning by studying (e. g., lectures, demonstrations, exercises, study and writing assignments, examinations), as well as for learning-bydoing (e. g., practica, research assignments, supervised work as a student). To facilitate the (re)design of curricula, it is advisable to translate the competence profile into a standard curriculum model that specifies the elements a curriculum should contain and which can serve as a direct model for comparison. The ENOP-model and the Euro-PsyT-model, previously referred to as "input models," can be seen as examples of this approach.

\section{Initial Professional Training}

Since competences can only be acquired in practice, i. e., by performing the required tasks, duties, and roles, there is a need for a system of professional training that allows graduates entering the field to learn from practice without carrying full responsibility for clients. Initial professional training should offer those with basic competences the opportunity to engage in professional 


\begin{tabular}{|c|c|}
\hline Category & Level \\
\hline \multicolumn{2}{|l|}{ Knowledge } \\
\hline Cognitive theory & (1) (2) (3) (4) (5) \\
\hline Personality theory & (1) (2) (3) (4) (5) \\
\hline Performance theory & (1) (2) (3) (4) (5) \\
\hline Career theory & (1) (2) (3) (4) (5) \\
\hline Job design theory & (1) (2) (3) (4) (5) \\
\hline \multicolumn{2}{|l|}{ Skills } \\
\hline Problem analysis skills & (1) (2) (3) (4) (5) \\
\hline Observation skills & (1) (2) (3) (4) (5) \\
\hline Oral communication skills & (1) (2) (3) (4) (5) \\
\hline Writing skills & (1) (2) (3) (4) (5) \\
\hline Team collaboration skills & (1) (2) (3) (4) (5) \\
\hline \multicolumn{2}{|l|}{ Attitudes } \\
\hline Respect for people & (1) (2) (3) (4) (5) \\
\hline Openness to criticism & (1) (2) (3) (4) (5) \\
\hline Involvement & (1) (2) (3) (4) (5) \\
\hline Customer orientation & (1) (2) (3) (4) (5) \\
\hline Integrity & (1) (2) (3) (4) (5) \\
\hline \multicolumn{2}{|l|}{ Abilities } \\
\hline Analytical reasoning & (1) (2) (3) (4) (5) \\
\hline Verbal reasoning & (1) (2) (3) (4) (5) \\
\hline Verbal fluency & (1) (2) (3) (4) (5) \\
\hline Distributed attention & (1) (2) (3) (4) (5) \\
\hline Emotional intelligence & (1) (2) (3) (4) (5) \\
\hline \multicolumn{2}{|l|}{ Personality traits } \\
\hline Emotional stability & (1) (2) (3) (4) (5) \\
\hline Conscientiousness & (1) (2) (3) (4) (5) \\
\hline Friendliness & (1) (2) (3) (4) (5) \\
\hline Flexibility & (1) (2) (3) (4) (5) \\
\hline Self-confidence & (1) (2) (3) (4) (5) \\
\hline \multicolumn{2}{|l|}{ Other characteristics } \\
\hline Personal work experience & (1) (2) (3) (4) (5) \\
\hline Interest in people & (1) (2) (3) (4) (5) \\
\hline Interest in business environments & (1) (2) (3) (4) (5) \\
\hline Democratic values & (1) (2) (3) (4) (5) \\
\hline Absence of psychopathology & (1) (2) (3) (4) (5) \\
\hline
\end{tabular}

\begin{tabular}{|l|l|}
\hline \multicolumn{2}{|l|}{ Category } \\
\hline \multicolumn{2}{|l|}{ Level } \\
\hline Identifying client needs & (1) (2) (3) (4) (5) \\
\hline Individual assessment & (1) (2) (3) (4) (5) \\
\hline Work place analysis & (1) (2) (3) (4) (5) \\
\hline Selection system design & (1) (2) (3) (4) (5) \\
\hline Organizational development & (1) (2) (3) (4) (5) \\
\hline Subcompetences & \\
\hline Interviewing & (1) (2) (3) (4) (5) \\
\hline Testing & (1) (2) (3) (4) (5) \\
\hline Job analysis & (1) (2) (3) (4) (5) \\
\hline Consultation & (1) (2) (3) (4) (5) \\
\hline Keeping documentation & (1) (2) (3) (4) (5) \\
\hline
\end{tabular}

\section{Figure 2}

Example of the competence profile for $\mathrm{W} \& \mathrm{O}$ psychologists (entry level).

work under the supervision of qualified psychologists. Supervision means that a qualified psychologist carries the full responsibility for the trainee vis-à-vis the client. But supervision also serves to promote the learning process by offering a role-model, coaching the trainee during socialization and performance of the work role, giving feedback and stimulating reflection, providing opportunities for consultation about technical and ethical questions, etc. The learning process can be fostered by using a training program that covers all major aspects of the professional role in a particular specialized area, or by task assignments offering critical learning opportunities. The function of the competence profile in initial professional training is to specify the gap to be bridged between the basic competences of the graduate, on the one hand, and the initial competences of the psychologist entering independent practice, on the other hand.

\section{Continued Professional Training}

The maintenance and further development of competence among those engaged in independent practice calls for ongoing training efforts. Like other professionals the psychologist needs to continue learning in order to keep abreast of developments in the discipline and the profession, changes in the type of clients dealt with or in 
the problems posed by the clients, and changes in the organization of practice. Further learning is also needed to develop existing expertise, either by specialization or by broadening its scope. Continued professional training (or continued professional development, $\mathrm{CPD}$ ) may take different forms. On the one hand, it may consist of updating knowledge by means of theory-based courses and refreshing and extending (or enhancing) skills and subcompetences by means of training courses and workshops. On the other hand, it may consist of mixed forms of self-directed learning, intervision, and coaching, which are typical for competence development in practice. Competence profiles can help in the design of continued professional training in a number of ways. In cases of specialization within a particular area the competence profile of the specialty will indicate which (sub)competences and which associated knowledge, skills, and attitudes to focus on-in much the same way as described above for initial professional training. One looks for a gap between what is present and what is needed. A second way is to apply the competence profile for the current specialty and look for opportunities to raise the level of competence by learning from reflection on everyday practice and changes in the professional setting or role. This may be supported by intervision and coaching. In this way there is no circumscribed gap to bridge, but rather an exploration of how existing competences can be deepened or extended, depending on the requirements of the professional situation. A third way is to update the existing competence profile or establish an additional specialized competence profile, in order to describe and analyze the content of the work and the demands posed by it. This would seem useful in cases in which a new specialty is developing, such as in the psychology of drug addiction or the psychology of knowledge work. In this case one would compare the required and present qualifications and build up the training in a manner that bridges the gap.

\section{Accreditation}

The basic idea underlying accreditation in psychology is that it helps to standardize and raise the professional competence of psychologists, as well as to guarantee a certain level of competence to the public. However, accreditation can be undertaken in different ways and with different purposes in mind. I would like to differentiate between institutional accreditation, initial individual accreditation, and periodic individual accreditation.

\section{Institutional Accreditation}

As suggested above, the easiest way to standardize and guarantee a psychologist's competence is to do it indirectly, i. e., by accrediting the educational institutions that offer a curriculum that enables students to become psychologists. This entails accreditation of psychology curricula offered by universities. It should be clear that not all teaching in psychology would fall within the scope of institutional accreditation as meant here. Many universities around the world offer programs and courses in psychology that do not aim to prepare students to become (practicing) psychologists. Obviously, one would only want to accredit curricula that do indeed pursue the aim of preparing graduates for independent psychological practice. The accreditation is indirect in that it focuses on the curriculum, including its structure, scope, content, level, didactics, and examination methods, but with the explicit purpose of guaranteeing the presence of basic competences, along with necessary subcompetences, knowledge, skills, and attitudes, as needed for entering supervised practice. This was referred to as an "input model" above. Thus, rather than examining the content of the basic competence profile as such, the accreditation process aims at the educational arrangements by which the university tries to ensure that graduates will meet the profile. The assessment can be guided by the same curriculum model as was mentioned before. This means that the curriculum model serves not only as a standard for curriculum development, but also as an assessment tool showing whether the requirements are met and identifying eventual deficiencies.

The logic of institutional accreditation as a means to achieve standardization and to guarantee of competence only works in combination with some system of quality assurance at the level of the institution itself. Thus, a check of the way in which the institution controls the teaching and examination process should be part of the accreditation procedure. Finally, it should be clear that institutional accreditation can only be awarded for a limited time. Both changes within the curriculum and in the policy and procedures of the university make it necessary to renew the accreditation after a certain period of time.

\section{Individual Accreditation-Initial}

A direct assessment of competence at the point of entry is required in order to ensure a sufficient level of competence among those entering independent practice. This was referred to above as an "output model." Because

European Psychologist, Vol. 7, No. 3, September 2002, pp. 192-202 (C) 2002 Hogrefe \& Huber Publishers 
practice always takes place within a particular area of specialization, assessment has to focus on the basic competences for that area. Unless subcompetences, knowledge, skills, and attitudes are already covered by institutional accreditation, these qualifications also have to be assessed. Competence profiles for the specialties define the qualities to be assessed. But an examination system is also needed to present individual candidates with questions and probes, tapping these qualities and converting their responses into measures of competence. This means a combination of knowledge tests, skill exercises, attitude questionnaires, and work simulations with an acceptable level of content validity. Since initial accreditation addresses the competence at the moment of entry, the examination results would have only limited validity. After a period of work in practice some form of recurrent re-accreditation would be necessary in order to ensure that the psychologist has maintained and perhaps enhanced his/her competence.

\section{Individual Accreditation-Periodical}

Periodic accreditation focuses entirely on the competences required for the particular area of specialization in which the psychologist is working. In this respect it differs from initial accreditation. The content of the assessment follows from the competence profile for the specialty. The examination procedure may be similar, but considering the importance of competence as demonstrated in practice, it is likely that greater emphasis is put on advanced competences demonstrated in simulations and the real work setting. The ways in which psychologists deal with a variety of settings and problems, and the degree to which they meet the demands on knowledge, skills, and attitudes when helping to solve the clients problem, lie at the heart of the assessment. This means less use of written examinations and greater reliance on work-based assessment (or evaluation) by experts. An optimal moment for reassessment is after 4 to 5 years of independent practice when a junior psychologist becomes a senior psychologist, although repeated accreditation at earlier or later times are also conceivable.

\section{Quality Assurance}

A final application of competence profiles lies in quality assurance of psychological services. Here the focus is no longer on the individual psychologist but rather on the organizational entity within which services are rendered. This entity may be an individual practice, a psy- chological department of a larger organization, or an independent clinic, laboratory, or consultancy. Quality assurance can take different forms, e. g., according to the ISO 9000 series. It will generally address services rendered, tools and procedures used, but also deal with the psychologists' competencies and continued professional training. The broader focus of quality assurance is attractive since it reminds us that the service received by the client does not depend only on the competence of the individual psychologist. Thus, the information given to clients, the way in which clients are received, the availability of diverse expertise, the degree of professional development, and collaboration with nonpsychologists may all have an impact on the quality of the service rendered to clients. Yet, an assessment of competences of psychologists-both at the initial point and periodically-would be part of any system of quality assurance in professional practice.

\section{Conclusion}

This article has shown that developing and maintaining the professional qualifications of European psychologists is not an merely issue of standardizing educational input or performance output. Psychologists first have to define the content of the profession and particularly the various forms of specialization across Europe. Next, competence profiles should be drawn up that define the competences psychologists should demonstrate at the point of entry into supervised work or the beginning of independent practice, and later stages of the career. Apart from competences, which relate to the ability to adequately perform tasks, duties, and roles, the profiles should also reveal the knowledge, skills, and attitudes required. The competence architecture model presented in this article would appear to offer a suitable base for making such competence profiles. The competence profiles of the kind discussed may be helpful in designing a system of professional development. They offer applications that reach well beyond the possibilities of input and output models. The main hindrance to using competence profiles currently is that insufficient empirical evidence is available on the work psychologists perform and on the demands posed to those employed in this profession. I would therefore like to conclude by recommending that psychologists devote more research to their own professional role and work activities, before taking efforts toward standardization too far. 


\section{Acknowledgment}

The author expresses his thanks to Ingrid Lunt and Ype Poortinga for their comments on an earlier version of the manuscript.

\section{References}

Anastasi, A. (1979). Fields of applied psychology (2nd ed.). New York: McGraw-Hill.

Bartram, D. (1996). Occupational standards and competencebased qualifications for professional applied psychologists in the U.K. European Psychologist, 1, 157-165.

Bartram, D. (2000a). Higher education and the delivery of standardsbased qualifications. Unpublished paper.

Bartram, D. (2000b). Standards-based qualifications. Paper presented to the Leonardo Euro-Psych Project. London, May 20, 2000.

British Psychological Society (1995). Professional psychology handbook. Leicester: British Psychological Society.

British Psychological Society (2001). A general introduction to the review of the national occupational standards for applied psychology. London: BPS/Cambridge/5S Consulting Group.

Consultative Working Group for Occupational Standards in Applied Psychology (1998). National occupational standards in applied psychology. Leicester: British Psychological Society.

ENOP (1988). European curriculum in work and organizational psychology. Reference model and minimal standards. Paris: ENOP/Maison des Sciences de l'Homme.

Fletcher, S. (1997). Analysing competence: Tools and techniques for analyzing jobs, roles and functions. London: Kogan Page.

Francis, R.D., \& Cameron, C. (1991). Handbook of professional psychology. Bowen Hills: Australian Academic Press.

Gael, S. (Ed.). (1988). Job analysis handbook for business, industry and government. New York: Wiley.

Green, A., Wolf, A., \& Leney, T. (1999). Convergence and divergence in European education and training systems. London: Institute of Education.

Hacker, W. (1998). Allgemeine Arbeitspsychologie. Psychische Regulation von Arbeitstätigkeiten [General work psychology. Mental regulation of work activities]. Bern: Hans Huber.

Hartley, J., \& Branthwaite, A. (Eds.). (2000). The applied psychologist (2nd ed.). Buckingham: Open University Press.

Hesketh, B. (2000). Prevention and development in the workplace. In S. Brown, \& R.W. Lent (Eds.), Handbook of counseling psychology (3rd ed., pp. 471-498). New York: Wiley.

Lunt, I. (2000). European project funded by the European Union under the Leonardo da Vinci program. European Psychologist, $5,162-164$.

Lunt, I., Bartram, D., Döpping, J., Georgas, J., Jern, S., Job, R., Lecuyer, R., Newstead, S., Nieminen, P., Odland, S., Peiró, J.M.,
Poortinga, Y., Roe, R., Wilpert, B., \& Herman, E. (2001a). EuroPsyT-A framework for education and training for psychologists in Europe. Brussels: EFPA.

Lunt, I., Baneke, R., Berdullas, M., Hansson, B., \& Nevalainen, V. (2001b). Laws and regulations for psychologists in European countries. Brussels: EFPA.

Mansfeld, R.S. (1996). Building competency models: Approaches for HR professionals. Human Resource Management, 35(1), 7-18.

Matthews, G., Davies, D.R., Westerman, S.J., \& Stammers, R.B. (2000). Human performance. Cognition, stress, and individual differences. Hove: Psychology Press.

National Council for Vocational Qualifications (1991). Guide to national vocational qualifications. London: NCVQ.

National Council for Vocational Qualifications (1995). NCVQ criteria and guidance. London: NCVQ.

Newstead, S., \& Makkinen, S. (1997). Psychology teaching in Europe. European Psychologist, 1, 14.

Peterson, R.L., McHolland, J.D., Bent, R.J., Davis-Russell, E., Edwall, G.E., Polite, K., Singer, D.L., \& Stricker, G. (Eds.). (1992). The core curriculum in professional psychology. Washington: American Psychological Association.

Pryzwansky, W.B., \& Wendt, R.V. (1999). Professional and ethical issues in psychology. Foundations of practice (1999). New York: Norton.

Pulverich, G. (Ed.). (1997). Inventory of regulations in the field of psychology in European countries. Bonn: Deutscher Psychologie Verlag.

Roe, R.A. (Ed.). (1984). Wat doet de psycholoog? [What does the psychologist do?]. Assen: Van Gorcum.

Roe, R.A. (1999a). Work performance. A multiple regulation perspective. In G. Cooper, \& I.T. Robertson (Eds.), International review of industrial and organizational psychology-1999 (pp. 231335). Chichester: Wiley.

Roe, R.A. (1999b). Competences, assessment and development. Unpublished document.

Roe, R.A., Coetsier, P., Levy-Leboyer, C., Peiró, J.M., \& Wilpert, B. (1994). The teaching of work and organizational psychology in Europe. Toward the development of a reference model. The European Work and Organizational Psychologist, 4, 355-365.

Roe, R.A. (2001). Competencies and competence management-Critique and proposal for a comprehensive theory-based approach. Paper presented at the 10th European Congress for Work and Organizational Psychology, Prague, May 16-19, 2001.

Roe, R.A. (2002). Competences-A key towards the integration of theory and practice in work psychology. Gedrag en Organisatie, $15,203-224$

Shepard, A. (2001). Hierarchical task analysis. London: Taylor \& Francis.

Spencer, L.M., \& Spencer, S.M. (1993). Competence at work. Models for superior performance. New York: Wiley. 